\title{
Association of tibiofemoral angle, quadriceps angle and body mass index in a selected adolescent population
}

\author{
${ }^{1}$ Joseph O Umunnah, ${ }^{1}$ Chukwudi M Ogbueche, ${ }^{2}$ Chigozie I Uchenwoke, ${ }^{2}$ Adaora J Okemuo
}

1. Department of Medical Rehabilitation, Faculty of Health Sciences and Technology, College of Medicine, Nnamdi Azikiwe University, Nnewi Campus, Anambra State, Nigeria.

2. Department of Medical Rehabilitation, Faculty of Health Sciences and Technology, College of Medicine, University of Nigeria, Enugu Campus, Enugu State, Nigeria. www.unn.edu.ng

\begin{abstract}
Background: Tibiofemoral angle (TFA) and quadriceps angle (QA) are important in the evaluation of patients with knee pathologies associated with these angles.

Objectives: This study investigated correlations among TFA, QA and body mass index (BMI) among Nigerian adolescent population.

Methods: A total of 519 (262 males and 257 females) adolescents aged between 10-18 years selected by stratified random sampling technique from some randomly selected schools in Nnewi metropolis. This study utilised the cross-sectional survey design. A height meter and bathroom weighing scale were used to collect data for BMI while a universal plastic goniometer was used to measure TFA and QA. Independent t- test, paired t-test and Pearson Product Moment Correlation were used to analyse the data obtained.

Results: Findings of this study showed there was significant difference between right and left $\mathrm{QA}$ of males $(\mathrm{t}=2.824 ; \mathrm{p}=$ 0.005), and females ( $\mathrm{t}=-2.012 ; \mathrm{p}=0.045)$ with the right $\mathrm{QA}$ been higher than the left in both males and females. Males have a higher TFA and QA ( $\mathrm{p}<0.05$ in all cases) than females. A significant negative correlation was found between BMI and right TFA ( $\mathrm{p}=0.034)$, and between TFA and QA $(\mathrm{p}=<0.0001)$.

Conclusion: TFA positively significantly correlated with QA, with males having higher QA and TFA than females. The obtained information is important in the assessment and management of knee pathologies associated with these angles.

Keywords: Tibiofemoral angle; quadriceps angle; body mass index; selected adolescent population.

DOI: https://doi.org/10.4314/ahs.v20i2.43

Cite as: Umunnah JO, Ogbueche CM, Uchenwoke CI, Okemuo AJ. Association of tibiofemoral angle, quadriceps angle and body mass index in a selected adolescent population. Afri Health Sci. 2020; 20(2): 891-896. bttps:// doi.org/10.4314/ahs.v20i2.43
\end{abstract}

\section{Introduction}

The anatomical tibiofemoral angle (TFA) represents one of the most reliable measures of angular alignment of the knee, as it has been found to give good correlation with the clinical TFA, which is determined radiologically ${ }^{1}$. The acute angle subtended at the point of intersection at the centre of the patella between the

\footnotetext{
Corresponding author:

Chigozie I Uchenwoke,

Department of Medical Rehabilitation,

Faculty of Health Sciences and Technology,

College of Medicine, University of Nigeria,

Enugu Campus. www.unn.edu.ng

Tel:+2348060254107

Email: chigozie.uchenwoke@unn.edu.ng
}

femoral axis and the axis of the tibia is referred to as the tibiofemoral angle (TFA) ${ }^{2}$. It has also been used to differentiate physiologic conditions from pathologic angular mal-alignment of the knee ${ }^{1}$. The Quadriceps angle ( $Q$ angle) is described as an angle with its apex at the patella, and formed between the ligamentum patellae and the extension of the line formed by the quadriceps femoris muscle resultant force ${ }^{3}$. The value of the Q- angle, if in excess of the normal is taken as an indicator of possible knee pathology and may also serve as a prognostic value in the management of these conditions ${ }^{4}$. The body mass index (BMI), or Quetelet index, is a reliable indicator of body fatness for most children and teenagers. It is defined as the individual's body mass divided by the square of their height - with the value universally being given in units of $\mathrm{kg} / \mathrm{m}^{25}$. A significant negative correlation has been established between the 
tibiofemoral angle and Body Mass Index ${ }^{2}$. A number of studies have determined the value of TFA ${ }^{2,6,7}$ and Q-angle $^{8,9}$ across various age groups in Nigeria. Only Bafor ${ }^{2}$ had, however correlated BMI and TFA establishing a negative correlation between the two variables. None of these previous studies investigated the relationship between BMI and Q-angle. This study was carried out to determine the relationship between Body mass index, Tibiofemoral angle and Q-angle among Nigerian adolescent population.

\section{Methods}

This cross-section survey was approved by the Nnamdi Azikiwe University, Awka and Nnamdi Azikiwe University Teaching Hospital Research Ethical Committee. Nine schools (5 private and 4 public) were selected using stratified random sampling from the list of 13 schools (7 private and 6 public schools) in Nnewi North Local Government Area of Anambra state. Five hundred and nineteen (519) participants (male $=262$ and female $=257$ ) aged between 10 and 18 years whose parents gave consent were involved in this study. Children with a history of musculo-skeletal disorders and those with obvious trauma to the lower limbs were excluded from the sampled population.

Tibiofemoral angle (TFA) and Quadriceps angle (Q-angle) was taken with universal goniometer. Each participant was examined in supine position. In supine position, the hips and knees were extended, the patella facing vertically upward, and the feet dorsiflexed to right angle. One arm of the goniometer was aligned to an imaginary line drawn from the anterior superior iliac spine to the middle of the patella (femoral alignment) for both TFA and Q-angle. The second arm was aligned to a line joining the middle of the patella to the middle of the ankle (centre point between medial and lateral malleoli), for TFA and the tibia tubercle for Q-angle. The centre of patella served as fulcrum for the goniometer. The acute angle sustained at respective intercessions was recorded as the TFA and Q- angle in degrees respectively.
Standard methods were also used to assess body weight $(\mathrm{kg})$ and body height $(\mathrm{m})$ with electronic weighing scale (Hana, Model BR9011; 120 X 0.01kg, China) and a plastic height meter (Invicta Plastic Limited, England) respectively. Research assistants (Postgraduate students of Physiotherapy department) were trained to ensure accurate measurements.

\section{Ethical considerations}

Ethical approval for this study was given by the Ethics Committee of Nnamdi Azikiwe University Teaching Hospital, Nnewi with letter number (NAUTH/CS/66/ VOL6/92). Prior to the day of data collection, written informed consent was obtained, through the participants, from their parents/guardians and each individual gave verbal assent to take part in the study. Visits to the schools were as agreed upon by the principals of the schools. At each of those visits, all the eligible students who had the consent of their parents/guardian were measured.

\section{Data analysis}

The data was summarized using descriptive statistics of mean and standard deviation, while independent t- test and Pearson Product Moment Correlation were used to analyze the data obtained. Level of significance was set at 0.05 . Prior to the utilization of the independent t-test, an evaluation of the normality of histograms was done as it is more appropriate for assessing normality in larger samples.

\section{Results}

The results from 519 paired limb measurements of tibio-femoral angle (TFA) and quadriceps angle (Q-angle) of normal participants (262 measurements from males and 257 measurements from females) aged $10-18$ years are presented.

The physical characteristics of the participants are presented in Table 1. The mean Body mass index (BMI), right and left tibiofemoral angles of the participants were $20.14 \pm 4.02 \mathrm{~kg} / \mathrm{m} 29.28 \pm 3.16^{\circ}$ and $9.16 \pm 3.23^{\circ} \mathrm{re}-$ spectively while the mean right and left quadriceps angles of all participants were $8.87 \pm 2.916^{\circ}$ and $8.75 \pm 2.91^{\circ}$ respectively. 
Table 1: Physical characteristics, Tibiofemoral angle and Quadriceps angle of all participants $(\mathrm{N}=519)$.

\begin{tabular}{|c|c|c|}
\hline Parameters & Mean & $\begin{array}{l}\text { Standard } \\
\text { Deviation }\end{array}$ \\
\hline Age(years) & 14.64 & \pm 1.76 \\
\hline Height (m) & 1.59 & $\pm \mathbf{0 . 1 0}$ \\
\hline Weight (kg) & $\mathbf{5 0 . 8 7}$ & \pm 11.19 \\
\hline BMI $\left(\mathrm{kg} / \mathrm{m}^{2}\right)$ & 20.14 & \pm 4.02 \\
\hline Right TFA ( $\left(^{\circ}\right)$ & 9.28 & $\pm \mathbf{3 . 1 6}$ \\
\hline Left TFA $\left({ }^{\circ}\right)$ & 9.16 & $\pm \mathbf{3 . 2 3}$ \\
\hline Right Q-A ( $\left(^{\circ}\right)$ & 8.87 & \pm 2.92 \\
\hline Left Q-A ( $\left.{ }^{\circ}\right)$ & 8.75 & \pm 2.91 \\
\hline $\begin{array}{l}\text { Key: } \\
\text { N= Number of participants } \\
\text { Q-A= Quadriceps angle } \\
\text { BMI = Body Mass Index } \\
\text { TFA= Tibiofemoral angle }\end{array}$ & & $\begin{array}{l}\mathrm{kg}=\text { kilogram } \\
\mathrm{kg} / \mathrm{m}^{2}=\text { kilogram per meter square } \\
\mathrm{m}=\text { meter } \\
\mathrm{o}^{\circ}=\text { degrees }\end{array}$ \\
\hline
\end{tabular}

Results showed no significant correlation between body mass index and left tibiofemoral angle, between body mass index and quadriceps angle but showed a significant negative correlation between body mass index and right tibiofemoral angle, and positive correlation between tibiofemoral angle and quadriceps angle as shown in Table 2.

For both sexes, there was significant gender difference in the mean values of the right and left TFA, right and left Q-angle between ( $\mathrm{p}<0.0001$ in all cases) as shown in Table 3. 
Table 2: Pearson's Product MomentCorrelation showing the relationship among Body Mass Index, Tibiofemoral angle and Quadriceps angle of all the participants. $(\mathrm{N}=519)$

\begin{tabular}{lcc}
\hline Variables & r - value & p - value \\
\hline BMI vs right TFA & $\mathbf{- 0 . 0 8 0}$ & $\mathbf{0 . 0 3 4}$ \\
BMI vs left TFA & $\mathbf{- 0 . 0 6 6}$ & $\mathbf{0 . 0 6 7}$ \\
BMI vs right Q-A & $\mathbf{- 0 . 0 6 1}$ & $\mathbf{0 . 0 8 3}$ \\
BMI vs left Q-A & & $\mathbf{0 . 1 7 8}$ \\
Right Q-A vs right TFA & $\mathbf{0 . 0 4 1}$ & $\mathbf{0 . 0 0 0 1} *$ \\
Left Q-A vs left & & \\
TFA & & $\mathbf{0 . 0 0 0 1 *}$ \\
& $\mathbf{0 . 7 7 8}$ & \\
\hline $\begin{array}{l}\text { Key: } \\
\text { * Significant Correlation } \\
\text { PPMC: Pearson's Product Moment Correlation } \\
\text { TFA: Tibiofemoral angle }\end{array}$ & & \\
Q-A: Quadriceps angle & &
\end{tabular}

Table 3: Independent $t$ - test Comparison of Right and Left TFA and Q-A of Male and Female Participants

\begin{tabular}{|c|c|c|c|c|}
\hline Variables & $\operatorname{Males}(N=262)$ & Females( $(N=257)$ & t-value & p - value \\
\hline & Mean \pm S.D & Mean \pm S.D & & \\
\hline Right Q-A & $9.72 \pm 2.63$ & $8.01 \pm 2.94$ & 6.980 & $0.0001 *$ \\
\hline Right TFA & $10.18 \pm 2.98$ & $8.37 \pm 3.09$ & 6.815 & $0.0001 *$ \\
\hline Left Q-A & $9.45 \pm 2.696$ & $8.02 \pm 2.951$ & 5.769 & $0.0001 *$ \\
\hline Left TFA & $10.05 \pm 3.070$ & $8.26 \pm 3.137$ & 6.580 & $0.0001 *$ \\
\hline \multicolumn{5}{|c|}{$\begin{array}{l}\text { Key: } \\
\text { TFA: Tibiofemoral angle } \\
\text { *: significant gender difference } \\
\text { Q-A: Quadriceps angle } \\
\text { N: Number of participants } \\
\text { S.D: Standard deviation }\end{array}$} \\
\hline
\end{tabular}




\section{Discussion}

This present study was carried out to document the relationship among tibiofemoral angle (TFA), quadriceps angle (Q-angle) and body mass index (BMI) and the possible gender differences among adolescents aged between 10 and 18 years in Nigeria using Nnewi, Anambra state as a case study.

The normative values for tibiofemoral angle and quadriceps angle across various age groups in Nigeria have already been established ${ }^{2,6,7,8,9}$. However very few studies have examined the correlation between tibiofemoral angle and body mass index ${ }^{2}$ while no study have been found to correlate quadriceps angle and body mass index. Although some studies ${ }^{10,11}$ suggested a relationship between tibiofemoral angle and quadriceps angle but did not specify in details the nature of the relationship. The current study found a significant negative correlation between BMI and right TFA only possibly because the weight of the body exerts a greater downward force on the knee joint. In addition to the possibility of the right lower limb being the dominant, this result is in consistent with findings from previous studies which reported a negative correlation between body mass index and tibiofemoral angle ${ }^{2}$. Though no significant correlation was found between body mass index and quadriceps angle, it is difficult to conclude on the findings obtained due to the non-existence of previous studies on the correlation between body mass index and quadriceps angle.

Our finding showed that there is a significant positive correlation between tibiofemoral angle and quadriceps angle of both knees and could be due to the fact that tibiofemoral angle, which represents the valgus angle formed by the anatomical axes of the femur and tibia, would move the patella medially relative to the anterior superior iliac spine (as the femur is in an adducted position) if too high and the tibial tuberosity laterally (as the tibia is in an abducted position) thus affecting the $\mathrm{Q}$ angle. Our finding also agrees with the theoretical proposal of Sarkar ${ }^{12}$ thasuggests that the values of quadriceps angle are as important as the values of tibiofemoral angle as a prognostic value during the management of associated disorder of the knee joint involving tibiofemoral or quadriceps angle.

This study was motivated by dearth of studies on body mass index, tibiofemoral angle, and quadriceps angle in children and few studies on correlation between body mass index and quadriceps angle. The mean value of tibiofemoral angle and quadriceps angle in this study when compared with the studies of $\mathrm{Bafor}^{2}, \mathrm{Tella}^{7}$, Ayaniyi ${ }^{8} \mathrm{Omololu}^{9}$ and $\mathrm{Akta}^{13}$, and were slightly lower. The differences could be as a result of numerous methodological variations, sample or population difference, ethnic and racial differences which may translate into considerable discrepancies.

This present study showed significant gender differences in the values of tibiofemoral angle and quadriceps angle between males and females. The males in this study presented with greater tibiofemoral and quadriceps angle than females. This result is not consistent with the findings Bafor $^{2}$, Tella ${ }^{7}$, Ayanniyi ${ }^{8}$ Omololu', and $\mathrm{Akta}^{13}$ which reported that females have a greater tibiofemoral angle value and quadriceps angle value than their male counterparts. This could be because of the longer distance between the pelvis and patella, relative to the distance from the patella to the tibia tuberosity and tibia axes in males, keeping in mind that males tend to be slightly taller than females.

There were also significant differences between the right and left quadriceps angle in both male and female participants. This results are consistent with the findings of Jaiyesimi ${ }^{14}$ who found the right quadriceps angle greater than the left owing to the possibility of limb dominance as majority had the right lower limb as the most used and are as such efficiently stronger but with the possibility of predisposing them to easily to pathological conditions associated with alterations in the Q-angle. No significant difference was found between right and left tibiofemoral angle for males and between right and left tibiofemoral angle for females this result is in consistent with findings from previous studies as such it is possible that the same references value can be used both for either limb in both sexes.

\section{Conclusion}

The results obtained suggests that Body mass index has a negative correlation with the right tibiofemoral angle. Tibiofemoral angle was found to correlate positively with quadriceps angle. However, this study revealed that values of tibiofemoral angle and quadriceps angle of the studied population were found to be lower than the values from previous studies. In general, males had higher values of tibiofemoral and quadriceps angle than females.

\section{Acknowledgements}

My sincere appreciation goes to the staff, alumni and students of the College of Health sciences, Nnewi for their support towards the outcome of this study. 


\section{Declaration of interest statement}

The authors report no conflicts of interest.

\section{Author's contributions}

Conception of research idea was done by JO Umunnah and CM Ogbueche. CM Ogbueche conducted the study under the supervision of JO Umunnah. CI Uchenwoke analysed the data, wrote the manuscript and approved the final version. AJ Okemuo participated in the study design, revision of manuscript and approved this final version. CM Ogbueche and AJ Okemuo participated in data collection, revision of manuscript and approved final version of the manuscript. CM Ogbueche drafted the first manuscript and involved in the final approval of the manuscript.

\section{References}

1. Salenius P, Vankka E. The development of tibiofemoral angle in children. Journal of Bone and Joint surgery. 1975; 57(2): 259-261

2. Bafor A, Omota B, Ogbemudia A. Correlation between Clinical Tibiofemoral angle and Body Mass Index in normal Nigerian children, International Orthopadeics. 2012; 36: 1247-1253

3. Raveendranath R, Shankar N, Narayanan S, Ranganath P, Devi R. Bilateral Variability of the Quadriceps Angle (Q angle) in an Adult Indian Population, Iranian Journal of Basic Medical Sciences. 2011; 14(5): 465-471

4. Schulthies SS, Francias RS, Fisher AG. Does the Q-angle reflect the force on the patella in the frontal plane? Physical Therapy Journal. 1995; 75:24-30

5. Mei et al Validity of body mass index compared with other body-composition screening indexes for the assessment of body fatness in children and adolescents. American Journal of Clinical Nutrition. 2002 Jun; 75(6): 978-85

6. Oyewole OO, Akinpelu AO, Odole AC. Development of Tibiofemoral angle in a Cohort of Nigerian
Children during the First 3 years of life; Journal of Children's Orthopaedics. 2012; 7(2):167-173

7. Tella BA, Akinpelu AO, Omololu AB. Normal values of Tibiofemoral angle in Nigerian Adolescents. The Internet Journal of Orthopaedic Surgery. 2010; 17 (1)

8. Ayanniyi O, Alonge IA, Ogwumike OO. Quadriceps angle in children with and without pes planus, International Journal of Health. 2009; 12(1)

9.Omololu BB, Ogunlade OS, Gopaldasani VK. Normal Q- angle in an adult Nigerian population. Journal of Orthopaedics and Related Research. 2009; 467 (8): 2073 $-2076$.

10. Nguyen AD, Boling MC, Levine B, Shultz SJ. Relationship between Lower extremity alignment and quadriceps angle. Clinical Journal of Sport Medicine. 2009; 19: 201-206

11. Kaya D, Doral MN. Is there any relationship between Q-angle and lower extremity malalignment? Acta Orthopaedica et Traumatologica Turcica, 2012: 46(6);416419.

12. Sarkar A, Razdan S, Vadav J, Bansal N, Kuhar S. and Pahuja S. Effect of isometric Quadriceps activiation on Q-angle in young females. Indian Journal of physiology and Pharmcology. 2009; 53 (3); 275-278

13. Akta B, Dhaval T, Nikita A, Ndili G. Q-angle in children population aged between 7 to 12 years, International Journal of Health Science Research. 2013; 3: 57-64

14. Jaiyesimi AO, Jegede OO. The influence of gender and leg dominance on the Q- angle among young adult Nigerians. African Journal of Physiotherapy and Rehabilitation Science. 2009; 1 (1): 18 -23.

15. Nguyen AD, Shultz SJ. Identifying relationships among lower extremity alignment characteristics. Journal of Athletic Training 2009; 44: 511-518

16. Sendur OF, Gurer G, Yildirim T, Ozturk E, Aydeniz A. Relationship of $\mathrm{Q}$ angle and joint hypermobility and $\mathrm{Q}$ angles in different positions. Clinical Rheumatology. 2006; 25:304-308. 